ISSN1331 - 677X (UDK 338)

May $30^{\text {th }}-$ June $1^{\text {st }} 2013$

\title{
CAN ECONOMIC GROWTH LAST? SERIOUSLY.
}

\section{Saša Stjepanovića}

aPh.d. Saša Stjepanović, Juraj Dobrila University of Pula, at Department of economics and tourism «Dr. Mijo Mirković» Pula.+38552377 067, sstjepan@unipu.hr

\section{ARTICLE INFO}

Keywords:

- Hansen test

- Energy consumption

- Economic growth,

- Sweden

\begin{abstract}
This study analyses the relationship between energy consumption and economic growth rate in the period 1980 - 2002 in Sweden. A specific question that is addressed throught this study is what is the threshold energy consumption rate for Sweden. In addition, we try to answer a question, if there is statistical significant relationship between energy consumption and growth. In this paper, we use econometric methodology of the threshold estimation proposed by Hansen (2000). Hansen, develops new tests for threshold effects, estimates the threshold parameter, and constructs asymptotic confidence intervals for the threshold parameter. The primary idea behind the Hansen test for threshold estimation is that an exogenously given variable, called «threshold variable», is used to split the sample in two groups or regime, which can or cannot be a regressor. This theory derives the asymptotic distribution of the Ordinary Least Squares (OLS) estimates of the threshold parameter.
\end{abstract}

Reference to this paper should be made as follows: Stjepanović. S. 2013. Can Economic Growth Last? Seriously, Ekonomska istraživanja - Economic Research Special Issue 2013 


\section{INTRODUCTION}

In the last twenty years, numerous studies have examined the causal relationships between energy consumption and economic growth. Until today, the empirical findings have been mixed or conflicting. One of the reasons for conflicting empirical findings regarding the relationship between energy consumption and economic growth lies in different approaches and different testing procedures employed for the analyses. Many of the earlier analyses employed simple log-linear models estimated by ordinary least squares (OLS) without any regard as the nature of the time-series properties of the variables involved. However, as has recently been proven, most economic time series are non-stationary in levels form (see Granger and Newbold, 1974). Thus, failure to account for such properties could result in misleading relationships among the variables. (Quaiser, 2009).

This study analyses the relationship between energy consumption and economic growth rate in the period of 1980-2002 in Sweden. A specific question that is addressed throughout this study is what is the threshold energy consumption rate for Sweden. In addition, we try to answer a question, if there is statistical significant relationship between energy consumption and growth. There are a large number of papers whose theme is non-stationarity in time series and threshold models and threshold estimation. Detecting non linearity in time series is a theme that occupies the mind of many authors, like Kun Chu (1988). Furthermore, Aruoba, Bocola and Schorfheide develop a new class of nonlinear time series models that can be used to evaluate the fit of DSGE models solved with second-order perturbation methods. Hinich, Mendes and Stone (2005), are trying to detect nonlinearity in financial time series with main interest to understand the generating process. Their one of the main test for testing linearity in time series is the Hinich Bispectrum Nonlinearity Test (HINBIN). Munir and Mansur (2009), analyses' non-linearity between inflation rate and GDP growth in Malaysia. What is specific for their research is that they tried to find a threshold inflation rate for Malaysia. Also, Theiler, Eubank, Longtin and Galdrikian (1992), trying to describe a statistical approach for identifying nonlinearity in time series. The method first specifies some linear process as a null hypothesis, then generates surrogate data sets, which are consistent with this null hypothesis, and finally computes a discriminating statistic for the original and for each of the surrogate data sets.

There are a lot of papers that study threshold effect and threshold models. One of them is from Lee, Seo and Shin (2010), where they try to develop a general method for testing treshold effects in regression models, using the sup-likelihood-ratio (LR)-type statistics. Another important paper is from Martinez and Olmo (2007), a nonlinear threshold model for the dependence of extremes of stationary sequences. In that paper, they argue that financial time series offer more information than that this hypothesis seems to supply. Bawa and Abdullahi (2010), try to find threshold effect of Inflation on economic growth in Nigeria. Moreover, Caner and Hansen (2004), are published paper about instrumental variable estimation of a threshold model. Existing estimation methods are confined to regression models, which require that all right-hand-side variables are exogenous. Their paper considers a model with endogenous variables but an exogenous threshold variable. There is also a very good paper about Threshold models in time-series analysis -30 years on, where that paper is a selective review on the development on the threshold model in a timeseries analysis over past 30 years or so. They first re-visits the motivation of the model, then they describe the various expressions of the model, and finally, they finish with some on-going research in the context of threshold volatility. 


\section{METHODS}

In this paper, we use econometric methodology of the threshold estimation proposed by Hansen (2000)' ${ }^{1}$. Hansen, develops new tests for threshold effects, estimates the threshold parameter, and constructs asymptotic confidence intervals for the threshold parameter. The basic idea behind the Hansen test for threshold estimation is that an exogenously given variable, called «threshold variable», is used to split the sample in two groups or regime, which can or cannot be a regressor. This theory derives the asymptotic distribution of the Ordinary Least Squares (OLS) estimates of the threshold parameter.

More specifically, consider a two-regime structural equation in treshold autoregression (TAR) model:

$$
\begin{aligned}
& y_{t}=\theta_{1}^{\prime} x_{t}+e_{1 t} \quad \text { if } \quad q_{t} \leq y, \\
& y_{t}=\theta_{2}^{\prime} x_{t}+e_{2 t} \quad \text { if } \quad q_{t}>y,
\end{aligned}
$$

Where denotes the threshold variable, splitting all the observed values into two classes or regimes. Terms and are dependent variable and explanatory variable ( $m$ vector) respectively. is the error term of property white-noise and denotes the threshold value. If we knew the model could be easily estimated by OLS. Since the threshold is unknown a priori so it should be estimated in addition to other parameters. Notice that when the threshold variable is smaller than the threshold parameter, the model estimates the equation (1). Similar, when the threshold variable is larger than the threshold parameter, the model estimates the equation (2).

Defining a binary variable where is the indicator function, with if occurs or otherwise, and setting, then equation (1) and equation (2) can be rewritten as a single equation:

$$
y_{t}=\theta^{\prime} x_{t}+\delta^{\prime} x_{t}(\gamma)+e_{t}
$$

Where, , and and are the regression parameters to be estimated. The residual sum of squares as a result of estimating the regression parameters can be written as follows:

$$
S_{1}(\gamma)=\hat{e_{t}}(\gamma)^{\prime} \hat{e_{t}}(\gamma)
$$

Hansen $(1996 ; 2000)$ recommends estimating by least squares technique. The easiest way to implement this procedure is through minimization of the sum of squared residuals as a func-

\footnotetext{
${ }^{1}$ Hansen (2000) presents a statistical estimation theory for threshold estimation in cross-section regression context, however, it can also be employed in a time-series analysis.
} 
tion of expected threshold value. Hence, we can write the optimum threshold value as follows:

$$
\gamma=\arg \arg \min S_{1}(\gamma)
$$

Conditional on the regression equation is linear in and, yielding the conditional OLS estimates of ( and by regression of dependent variable on explanatory variables. Following the foregoing procedure, linear equation (6):

$$
G D P_{t}=\beta_{0}+\beta_{1} \text { Energycons }_{t}+\beta_{2} \text { Population }_{t}-\beta_{3} \text { Import }_{t}+u_{t}
$$

can be expressed as a nonlinear equation under a two-regime threshold autoregression (TAR) model as follows:

$$
\begin{aligned}
& \text { GDP }_{t}=\left(\beta_{10}+\beta_{11} \text { Energycons }_{t}+\beta_{12} \text { Population }_{t}-\beta_{13} \text { Import }_{t}\right) d\left[q_{t} \leq \gamma\right]+ \\
& \left(\beta_{20}+\beta_{21} \text { Energycons }_{t}+\beta_{22} \text { Population }_{t}-\beta_{23} \text { Import }_{t}\right) d\left[q_{t}>\gamma\right]+e_{t}^{*}
\end{aligned}
$$

From, equation (7), the optimal threshold value can be determined by obtaining the threshold value that minimizes the residual sum of squares (RSS). Since the main objective of this paper is to investigate the energy consumption threshold effect in the relationship between energy consumption and economic growth in Sweden, the annual growth rate of energy consumption is employed as the threshold variable in the analysis. (Quaiser, 2009)

\section{EMPIRICAL RESULTS}

Prior to presenting the results, it is important to consider whether the variable under consideration is stationary. We test for stationarity to ensure that the variable used in the regression is not subject to spurious correlation. The Augmented Dickey-Fuller unit root test is used to investigate the stationarity status of variable energy consumption. Null Hypothesis is that Energy consumption or ENECONS has a unit root. With probability $=0.0005$ we can conclude that our variable does not have unit root in first difference. Moreover, we can see that GDP whit probability = 0.0005 we can conclude that this variable does not have unit root in first difference. 
TABLE 1. UNIT ROOT TEST

\section{Null Hypothesis: ENECONS has a unit root}

Exogenous: Constant

Lag Length: 4 (Automatic - based on SIC, maxlag=4)

t-Statistic Prob.*

Augmented Dickey-Fuller test statistic

$-5.364072$

0.0005

Test critical values:

$1 \%$ level

$5 \%$ level

$-3.857386$

$10 \%$ level

$-3.040391$

$-2.660551$
*MacKinnon (1996) one-sided p-values.

Augmented Dickey-Fuller Test Equation

Dependent Variable: D(ENECONS)

Method: Least Squares

Date: 09/10/13 Time: 10:12

Sample (adjusted): 19852002

Included observations: 18 after adjustments
Coefficient

ENECONS(-1)

D(ENECONS(-1))

D(ENECONS(-2))

D(ENECONS(-3))

D(ENECONS(-4))

C
R-squared

Adjusted R-squared

S.E. of regression

Sum squared resid

Log likelihood

F-statistic

-1.416900
0.543212
0.410527
0.533489
0.394881
360.5291

Std. Error

t-Statistic

Prob.

\subsection{6}

0.173821

0.158950

0.165205

0.165204

67.16884

0.749508

Mean dependent var

$-5.364072$

0.0002

3.125126

0.0088

2.582735

0.0240

0.0072

0.0341

0.0002
0.372222

6.395845

5.774352

6.071143

5.815276

1.425876

Prob(F-statistic) Source: Author Calculation 
Saša Stjepanović

TABLE 2. UNIT ROOT TEST

\section{Null Hypothesis: $D(L N G D P)$ has a unit root}

Exogenous: Constant

Lag Length: 1 (Automatic - based on SIC, maxlag=4)

Augmented Dickey-Fuller test statistic

t-Statistic

Prob.*

Test critical values:

1\% level
$5 \%$ level
$10 \%$ level

$-3.551597$

0.0172

$-3.808546$

$-3.020686$

$-2.650413$

*MacKinnon (1996) one-sided p-values.

Augmented Dickey-Fuller Test Equation

Dependent Variable: D(LNGDP,2)

Method: Least Squares

Date: 11/17/13 Time: 09:37

Sample (adjusted): 19832002

Included observations: 20 after adjustments

\begin{tabular}{|c|c|c|c|c|}
\hline Variable & Coefficient & Std. Error & t-Statistic & Prob. \\
\hline $\mathrm{D}(\operatorname{LNGDP}(-1))$ & -0.726892 & 0.204666 & -3.551597 & 0.0025 \\
\hline $\mathrm{D}(\operatorname{LNGDP}(-1), 2)$ & 0.479597 & 0.205138 & 2.337926 & 0.0319 \\
\hline \multirow[t]{2}{*}{ C } & 0.015846 & 0.005343 & 2.965914 & 0.0087 \\
\hline & 0.436915 & \multicolumn{2}{|l|}{ Mean dependent var } & 0.000385 \\
\hline R-squared & 0.370669 & \multicolumn{2}{|l|}{ S.D. dependent var } & 0.017284 \\
\hline ression & 0.013711 & \multicolumn{2}{|l|}{ Akaike info criterion } & -5.603724 \\
\hline red resid & 0.003196 & \multicolumn{2}{|l|}{ Schwarz criterion } & -5.454365 \\
\hline lood & 59.03724 & \multicolumn{2}{|l|}{ Hannan-Quinn criter. } & -5.57456 \\
\hline & 6.595399 & \multicolumn{2}{|l|}{ Durbin-Watson stat } & 1.876359 \\
\hline atistic) & 0.007584 & & & \\
\hline
\end{tabular}

Source: Author Calculation 
Estimation of the threshold parameter is not obvious as the dummy variable is a discontinuous function. Hence, to obtain an estimator minimazing the sum of squares or maximazing the loglikelihood, an analytical form can't be derived, nor can usual optimisation algorithms be used, as the objective function is highly erratic.

A solution is obtained through concentration of the objective function. As the slope estimators given a threshold are OLS, one can reduce the problem by concentrating out the minimization problem through and the corresponding sum of squares. The objective function becomes:

$$
\hat{\theta}=\operatorname{argminSSR}(\theta)
$$

Minimization of equation (8) is done through a grid search: the values of the variable are sorted, a certain percentage of the first and last values is excluded to ensure a minimal number of observations in each regime, the SSR is estimated for each selected value and the one that minimize the SSR is taken as the estimator. In our case we can see below that our minimize SSR is 1027.449 for data 245.3 , and so that is our estimator. This method has received differnet name in the literature such as concentrated LS, conditional LS.

TABLE 3. CONCENTRATED LS, CONDITIONAL LS

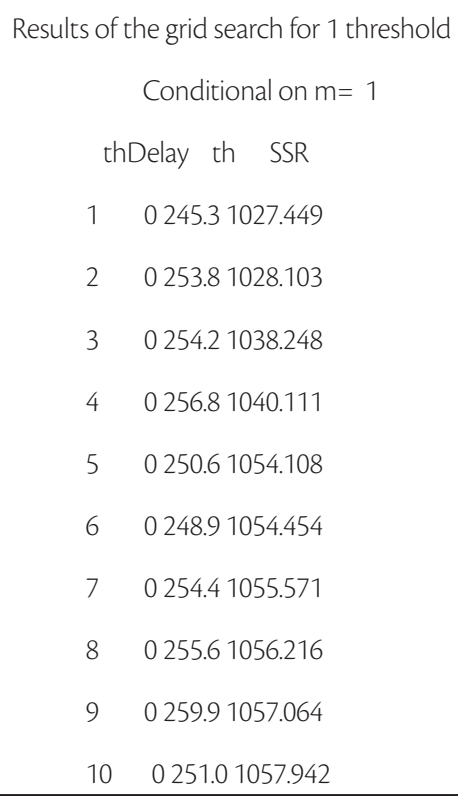

Source: Authors calculation 


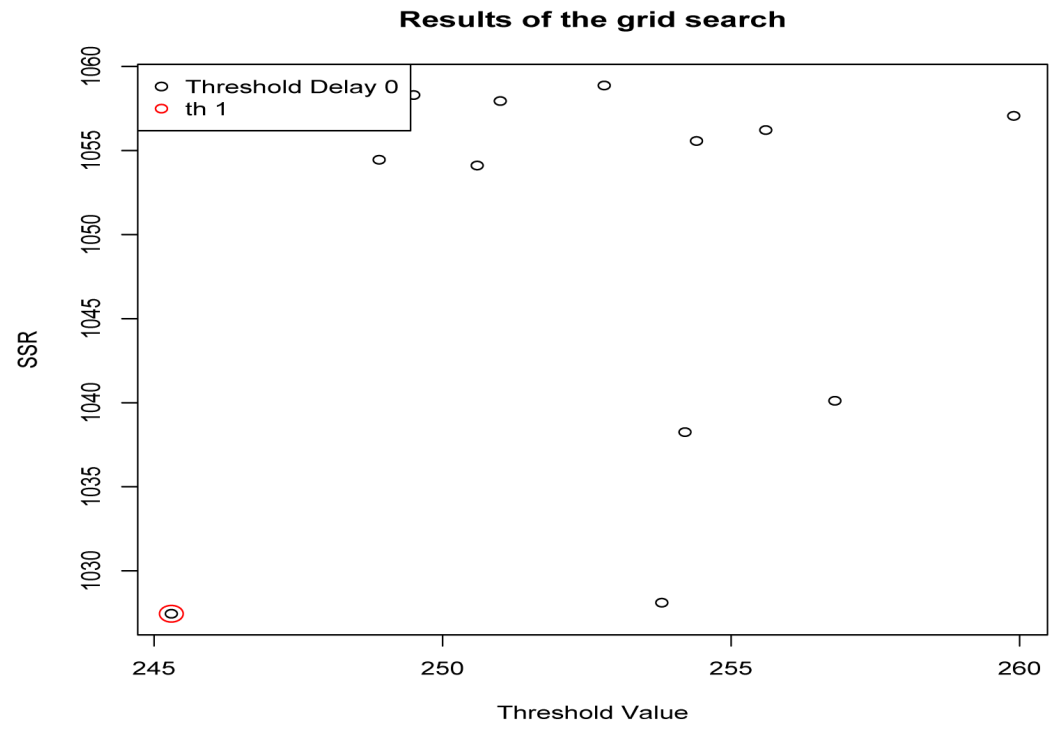

FIGURE 1. GRID SEARCH FOR THRESHOLD VALUE

Source: Author calcualtion

Figure 1. shows the output of the grid search and illustrates the erratic behavior of the objective function. Once the threshold has been estimated, it can be plugged into the SETAR function. Self-exciting threshold autoregressive model (SETAR), introduced by Chan (1983) and discussed extensively in Tong (1990). In the SETAR model, the autoregressive coefficients take different values depending on whether the previous value is above or under a certain threshold value, thus exhibiting regime switching dynamics. Hence, the linear adjustment process:

$$
\varepsilon_{t}=\rho \varepsilon_{t-1}+u_{t}
$$

is extended as:

$$
\varepsilon_{t}=\left\{\begin{array}{c}
\rho L \varepsilon_{t-1}+u_{t} \text { if } \varepsilon_{t-1} \leq \theta_{L} \\
\rho M \varepsilon_{t-1}+u_{t} \text { if } \theta_{L} \leq \varepsilon_{t-1} \leq \theta_{H} \\
\rho H \varepsilon_{t-1}+u_{t} i f \theta_{H} \leq \varepsilon_{t-1}
\end{array}\right\}
$$

This is actually a piecewise linear model where three different $A R(1)$ processes are estimated depending on the state of the variable at time $t-1$. Autoregressive parameters are denoted with subscript L, M and $\mathrm{H}$ standing for Low, Middle and High regime, and they differ whether the variable was below the lower threshold, between the lower and upper threshold, or above the higher. This leads to some further remarks:

- The threshold effect is present when and and as long as where $b=\mathrm{L}$ or $\mathrm{H}$.

- The SETAR model nest the AR when . 
TABLE 4. SELF-EXCITING THRESHOLD AUTOREGRESSIVE MODEL FOR ENERGY CONSUMPTION IN SWEDEN

Non linear autoregressive model

SETAR model ( 2 regimes)

Coefficients:

Low regime:

phiL.1 const L

0.3381301160 .4797237

High regime:

phiH.1 const H

0.709097673 .6786023

Threshold:

-Variable: $Z(t)=+(1) X(t)$

-Value: 245.3 (fixed)

Proportion of points in low regime: $18.18 \%$

High regime: $81.82 \%$

Residuals:

Min 1Q Median 3Q Max

$\begin{array}{lllll}-17.3230 & -3.9810 & -1.7294 & 4.7852 & 16.6827\end{array}$

Fit:

residuals variance $=44.67, \mathrm{AIC}=95, \mathrm{MAPE}=2.13 \%$

Coefficient(s):

Estimate Std. Error t value $\operatorname{Pr}(>|t|)$

const L 160.47972108 .688811 .47650 .15619

$\begin{array}{lllll}\text { phiL.1 } & 0.33813 & 0.45829 & 0.7378 & 0.46965\end{array}$

const H $73.6786072 .44398 \quad 1.01700 .32191$

phiH.1 $0.70910 \quad 0.283152 .50430 .02154$ *

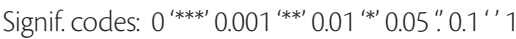

Threshold

Variable: $Z(t)=+(1) X(t)$

Value: 245.3 (fixed)

Source: Author calculation 
In Table 4. we see the results for threshold autoregressive model for energy consumption in Sweden. As result we see that value 245.3 presents a threshold value. Bootstrap $p$-value is 0.0214 which indicates that threshold exists.

The empirical results strongly suggest the existence of the one threshold value beyond which energy consumption exerts a negative effect on economic growth. This implies there is non-linear relationship between energy consumption and economic growth in Sweden. Our result point to the fact that energy consumption may promote economic growth when is below 245.3 millions of Btu. However, energy consumption doesn't have the positive impact on economic growth when it is above the threshold level of 245.3 millions of Btu.

TABLE 3. REGRESSION RESULTS OF ENERGY CONSUMPTION ON GDP GROWTH (1980-2002)

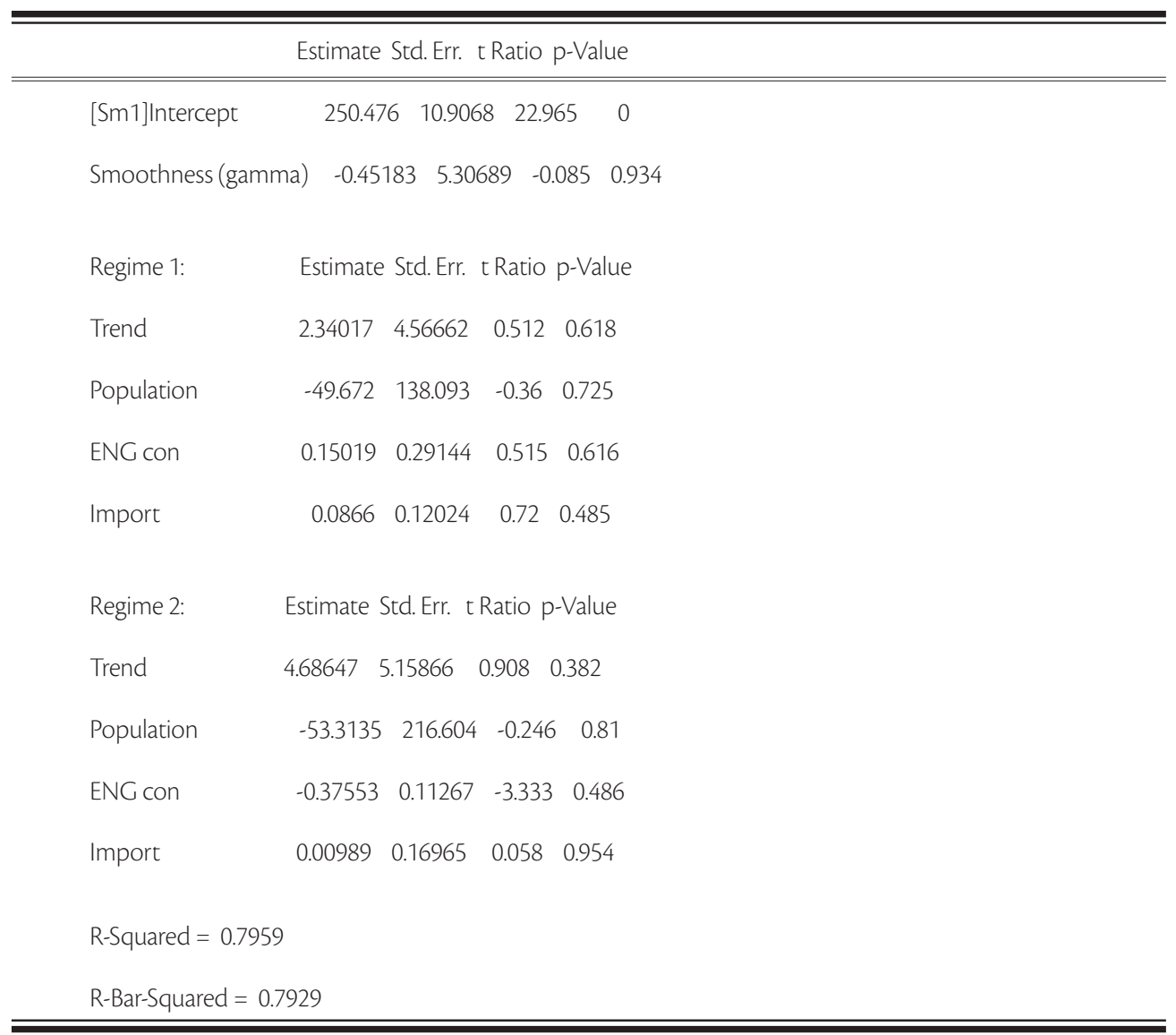

Source: Author calculation

The empirical results obtained from the estimation of the linear model show that energy consumption has significant positive impact on growth rate of GDP. As is in linear specification, the treshold model also reveals that energy consumption has a same significant impact on growth. However, both magnitude and sign of the energy consumption coefficient depends on the level of energy consumption. In the low - energy consumption regime, when energy consumption is below 245.3 millions of Btu, the marginal impact of energy consumption on growth is significantly positive (0.15019). That illustrates that under low-energy consumption regime, on average, a $1 \%$ 
increase in energy consumption in Sweden leads to increase in the economic growth by $0.15 \%$. However, when energy consumption is higher than threshold level, 245.3 millions of Btu., energy consumption has a significant negative effect on economic growth, as the coefficient is -0.37553 . This suggest that under high-energy consumption regime, on average, a 1\% increase in energy consumption leads to a decline in the economic growth by $0.375 \%$. The estimated coefficients, in two regime models, of ENG con not only differ statistically from zero but also highly significant at $p<0.05$. Note that population has a negative effect and import has a positive effect on economic growth regardless of the energy consumption regimes.

\section{CONCLUSION}

This paper analyses the relationship between energy consumption and economic growth in Sweden for the time period of 1980 until 2010, using new econometric methods (Hansen 1996; 2000) that provide appropriate procedures for estimation and inference.

The empirical results strongly suggest the existence of one threshold value beyond which energy consumption exerts a negative effect on economic growth. This implies there is non-linear relationship between energy consumption and economic growth for Sweden. Result in this paper point at the fact that energy consumption may promote economic growth when is below 245.3 millions of Btu. However, energy consumption is detrimental to economic growth when it is above threshold effect. In conclusion, the policy implication derived from this study is that it is desirable to keep the energy consumption rate below the threshold level in Sweden, as it may help sustainable growth. Using structural break technique, this study shows that the effect of energy consumption rate on economic growth is not only negative in high-energy consumption environment, but in low energy consumption environment, it can also be positive and more significant.

\section{REFERENCES}

Abdulnasser, H. J., Manuchehr, I., (2005) «Energy consumption and economic growth in Sweden: A leveraged bootstrap approach », International Journal of Applied Econometrics and Quantitative Studies, Vol. 2 - 4.

Aruoba, S. B., Bocola, L., Schorfheide, F., (2011) «A new class of nonlinear time series models for the evaluation of DSGE models», FRB-NBER DSGE Conference;

Bawa, S., Abdullahi, I. S., (2012) «Threshold effect of inflation on economic growth in Nigeria», CBN Journal of Applied Statistics, Vol. 3, No. 1,;

Caner, M., Hansen, B. E., (2004) «Instrumental variable estimation of a threshold model», Econometric Theory, Cambridge University Press, Vol. 20, pp. 813-843.

Hansen, B. E., (1999), «Threshold effects in non-dynamic panels: Estimation, testing and inference», Journal of Econometrics, Vol. 93, Issue: 2, pp $345-368$.

Hinich, M. J., Mendes, E. M., Stone, L., (2005) «Detecting nonlinearity in time series: Surrogate and bootstrap approaches», Journal of the American Statistical Association, Volume 9, Issue 4;

Martinez, O., Olmo, L., «A nonlinear threshold model for the dependence of extremes of stationary sequences», Discussion paper series, Department of Economics, City University, Northampton Square, London; 
Rodrigues, P. M. M., Salish, N., (2011), «Modeling and forecasting interval time series with Threshold models: An application to S\&P500 Index returns», Banco de Portugal, Economics and Research Department, Working paper series, Num. w201128.

Sokbae, L., Hwan Seo, M., Shin, Y., (2011) «Testing for threshold in regression models.» Journal of the American Statistical Association, Volume 106, Issue 493,;

Qaiser, M., Mansur, K., (2009) «Non-linearity between inflation rate and GDP growth in Malaysia», Economisc Bulletin, Vol. 29, No. 3, pp. 1555-1569.

Theiler, J., Eubank, S., Longtin, A., Galdrikian, B., Farmer, J. D., (1992), «Testing for nonlinearity in time series: the method of surrogate data», Physica, D. 58, pp. 77-94, North-Holland.

Zivot, E., Wang, J., (2006), «Nonlinear Time series models», Modeling Financial Time Series with S-PLUS, Springer New York, pp. 653 - 712.

Tong, H., (2010), «Threshold models in time series analysis - 30 years on », Research report, Serial No. 471, The University of Hong Kong, Department of statistics and actuarial science.

Zapata, H. O., Gauthier, W. M.o (2003), «Threshold models in theory and practice», Selected paper prepared for presentation at the Southern Agricultural Economics Association Annual Meeting, Mobile, Alabama. 